\title{
Erratum zu: Ein theoretischer und empirischer Überblick über die Entwicklung von Stereotypen und ihre Konsequenzen im Schulkontext
}

Sarah E. Martiny und Laura Froehlich

\section{Erratum zu: \\ Kapitel 1 In: S. Glock und H. Kleen (Hrsg.), \\ Stereotype in der Schule, https://doi.org/10.1007/978-3-658-27275-3_1}

Der Name der Autorin Laura Froehlich wurde in diesem Buch zunächst irrtümlich mit „ö“ geschrieben (Laura Fröhlich). Dieser Fehler wurde jetzt im Inhaltsverzeichnis, in Kapitel 1 und im Autor*innenverzeichnis korrigiert. 